\title{
SAND $-96-8452 C$ \\ THERMAL DECOMPOSITION OF HMX: LOW TEMPERATURE REACTION KINETICS AND THEIR USE FOR ASSESSING RESPONSE IN ABNORMAL THERMAL ENVIRONMENTS AND IMPLICATIONS FOR LONG-TERM AGING
}

RICHARD BEHRENS* AND SURYANARAYANA BULUSU**

*Sandia National Laboratories, Combustion Research Facility, Livermore, CA 94551

** Energetic Materials Division, U.S. Army, ARDEC, Dover, NJ 07801-5001

\begin{abstract}
The thermal decomposition of HMX between $175^{\circ} \mathrm{C}$ and $200^{\circ} \mathrm{C}$ has been studied using the simultaneous thermogravimetric modulated beam mass spectrometer (STMBMS) apparatus with a focus on the initial stages of the decomposition. The identity of thermal decomposition products is the same as that measured in previous higher temperature experiments. The initial stages of the decomposition are characterized by an induction period followed by two acceleratory periods. The Arrhenius parameters for the induction and two acceleratory periods are $(\log (\mathrm{A})=18.2 \pm 0.8, \mathrm{Ea}=48.2 \pm 1.8 \mathrm{kcal} / \mathrm{mole}),(\log (\mathrm{A})=17.15 \pm 1.5$ and $\mathrm{Ea}=48.9 \pm 3.2$ $\mathrm{kcal} / \mathrm{mole}),(\log (\mathrm{A})=19.1 \pm 3.0$ and $\mathrm{Ea}=52.1 \pm 6.3 \mathrm{kcal} / \mathrm{mole})$, respectively. This data can be used to calculate the time and temperature required to decompose a desired fraction of a sample that is being prepared to test the effect of thermal degradation on its sensitivity or burn rates. It can also be used to estimate the extent of decomposition that may be expected under normal storage conditions for munitions containing HMX. This data, along with previous mechanistic studies conducted at higher temperatures, suggest that the process that controls the early stages of decomposition of HMX in the solid phase is scission of the $\mathrm{N}-\mathrm{NO}_{2}$ bond, reaction of the $\mathrm{NO}_{2}$ within a "lattice cage" to form the mononitroso analogue of HMX and decomposition of the mononitroso HMX within the HMX lattice to form gaseous products that are retained in bubbles or diffuse into the surrounding lattice.
\end{abstract}

\section{INTRODUCTION}

Understanding the thermal decomposition of HMX (I) is important for developing models to predict the response of munitions in abnormal thermal environments and to obtain an understanding of the chemical processes that control its long-term degradation.

The objective of this work is twofold. First, we seek to develop a model that can be used to estimate the extent of thermal decomposition of HMX as a function of time and temperature. This model can be used to guide experiments that are aimed at determining the response of degraded explosives or propellants that contain HMX. For example, to predict the violence of reaction that occurs after ignition in a 'slow cookoff' event, it is important to know the high pressure burn rate characteristics of the<smiles>O=[N+]([O-])N1CN([N+](=O)[O-])CN([N+](=O)[O-])CN([N+](=O)[O-])C1</smiles>

(I) degraded materials. These results will provide information on the state of the thermally degraded material just prior to the ignition event. Second, we wish to ascertain the extent and characteristics of decomposition that may occur at lower temperatures which could affect the long-term aging of components containing HMX. In this work the temperature dependence of the global rates of decomposition of $\delta$-HMX will be determined and the results will be used to determine the lower limit on the rate of decomposition at storage conditions assuming that the reaction kinetics of $\delta$-HMX is similar to that of $\beta$-HMX.

\section{INSTRUMENTATION AND METHODS}

A description of the STMBMS apparatus and the experimental procedures that are used in this study have been described previously. ${ }^{1,2}$ For this study, HMX was decomposed in reaction cells

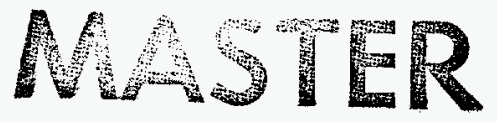




\section{DISCLAMMER}

Portions of this document may be illegible in electronic image products. Images are produced from the best available original document. 
using orifice diameters ranging from 10 to $100 \mu$ and 5 to $10 \mathrm{mg}$ samples of HMX that have a purity of greater than $99 \%$. The global rate of decomposition was extracted from the weight loss data measured with a microbalance after correction for evaporation of HMX.

\section{HMX THERMAL DECOMPOSITION PROCESS}

Using the described method, we have previously conducted extensive studies on the thermal decomposition of $\mathrm{HMX}^{3,4}$ and $\mathrm{RDX}^{5,6}$ in an effort to determine the reaction mechanisms that control the decomposition of these two cyclic nitramines.

\section{PREVIOUS RESULTS}

For RDX in the liquid phase (m.p. $200^{\circ} \mathrm{C}$ ), the gaseous products have been identified and their rates of formation have been measured and from these results a reaction mechanism consisting of four parallel reaction pathways were found to control the decomposition of RDX in the liquid phase. Details of the RDX decomposition mechanism have been published.5,6 In the solid phase, RDX was found to decompose through an intermediate that is the mononitroso analogue of RDX, hexahydro-1-nitroso-3,5-dinitro-s-triazine (ONDNTA).

In contrast to RDX, HMX liquefies between $270^{\circ}$ and $280^{\circ} \mathrm{C}$ and undergoes substantial decomposition in the solid phase. The identity and rates of formation of the products formed in the thermal decomposition of HMX have been determined and a qualitative model describing the

process has been developed. ${ }^{3}$ The thermal decomposition process of HMX is illustrated with the data shown in Figure 1. The main decomposition products are $\mathrm{H}_{2} \mathrm{O}, \mathrm{N}_{2} \mathrm{O}, \mathrm{CH}_{2} \mathrm{O}$, NO and $\mathrm{CO}$. The temporal behavior of the gas formation rates of each of the products is characterized by the following sequence: 1) an induction period, 2) an increasing rate of formation between 0 and $10 \%$ decomposition, 3) a faster increasing rate of decomposition between $10 \%$ and $30 \%$ decomposition and a decreasing rate of gas formation after $40 \%$ decomposition. Products formed at smaller rates of formation but with similar temporal behaviors include: (CH3) $2 \mathrm{NNO}$, the mononitroso analogue of HMX (1-nitroso-3,5,7-trinitro$1,3,5,7$-tetrazocine) and several

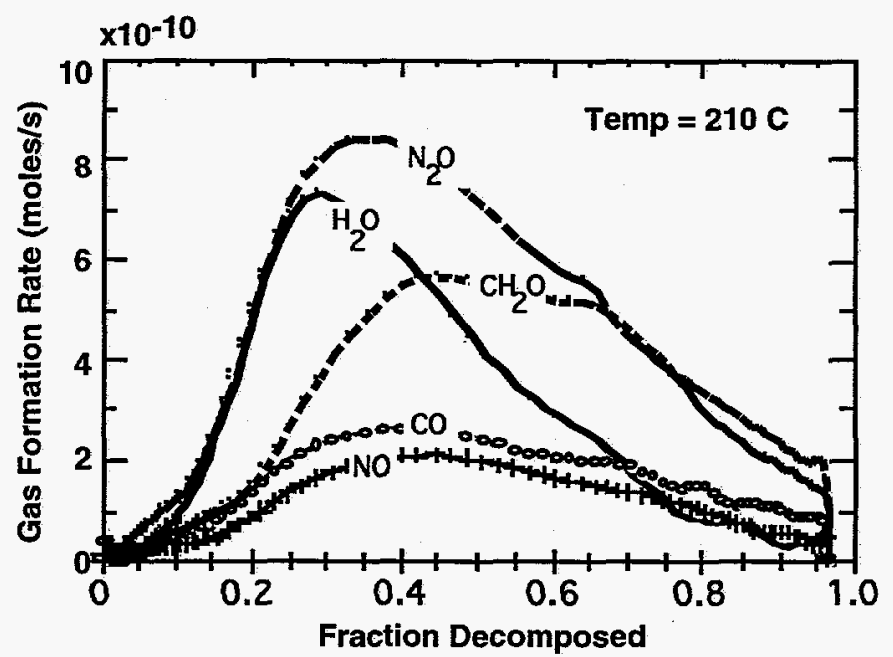

Figure 1. Gas formation rates of the products from the thermal decomposition of $\mathrm{HMX}$ at $210^{\circ} \mathrm{C}$. The duration of the decomposition process is about 37000 seconds.

formamides. The temporal behavior of the decomposition process during the induction period is illustrated with data from the decomposition of a deuterium labeled analogue of HMX, as shown in Figure 2. From this figure one observes a period of time in which the rates of formation of $\mathrm{N}_{2} \mathrm{O}$ and $\mathrm{CD}_{2} \mathrm{O}$ are low and constant with time. The time at which the gas formation rates first reach a constant value coincides with attaining an isothermal temperature of $235^{\circ} \mathrm{C}$ in the sample. The time period between the time that the isothermal temperature is reached and when the $\mathrm{N}_{2} \mathrm{O}$ signal first starts to increase is referred to as the induction period. The gas formation rates of $\mathrm{N}_{2} \mathrm{O}$ and $\mathrm{CH}_{2} \mathrm{O}$ during the induction period arise from the decomposition of $\mathrm{HMX}$ in either the gas phase or on the surface of the particles.

During the induction period of HMX the material is somehow transformed to a new state that undergoes more rapid decomposition. This transformation could be a nucleation process as observed in the decomposition of many inorganic salts in which nuclei are formed and destroyed 
while those that reach a certain critical diameter form the basis for the accelerating rate of decomposition as the nuclei grow. The transformation may also be due to the slow decomposition of the HMX within the lattice and the permeation of its gaseous products through the crystal structure, weakening the crystal structure, and leading to the release of gaseous products and the more rapid decomposition of noncrystalline material. This latter mechanism is consistent with the observation of the mononitroso analogue of RDX in the decomposition of RDX in the solid phase and the delay time observed for the onset of rapid decomposition during its decomposition as discussed in a previous paper. ${ }^{5}$ It is important to note that the HMX must be undergoing some significant change during the induction period. The acceleratory phase of the decomposition process marks a transition to a more rapid decomposition process. During this phase the HMX undergoes a more rapid rate of decomposition.

Our previous work on the decomposition of HMX in the solid phase was conducted over a temperature range from $210^{\circ}$ to $235^{\circ} \mathrm{C}$. This work was extended to higher temperatures to investigate the qualitative behavior of HMX decomposition in the liquid phase. ${ }^{7}$ The work covered in this paper extends the thermal decomposition measurements to lower temperatures. Since the objectives of the study are to obtain data to characterize the state of HMX under abnormal thermal conditions and to investigate the behavior of HMX during long-term aging, it is necessary to measure only the induction period and its early stages in particular, in these studies.

\section{NEW HMX LOWER TEMPERATURE DATA}

Experiments on the decomposition of HMX between $175^{\circ}$ and $200^{\circ} \mathrm{C}$ have been conducted to add to the database on its decomposition behavior. The general behavior is quite similar to that observed in the previous work as can be seen from Figure 3 for the decomposition of HMX at $182^{\circ} \mathrm{C}$. The ion signals representing the evolution of $\mathrm{N}_{2} \mathrm{O}$ and $\mathrm{CH}_{2} \mathrm{O}$ are very similar to the data collected at higher temperatures. In this case the induction period, as determined by the time at which the $\mathrm{N}_{2} \mathrm{O}$ signal first increases, is approximately 60,000 seconds. As the $\mathrm{N}_{2} \mathrm{O}$ signal increases, it is characterized by two different sets of increasing rates, with the first set being less than the second. This is typical of all of the data collected in the different experiments at lower temperatures.

Comparing the induction time of $\mathrm{N}_{2} \mathrm{O}$ to $\mathrm{CH}_{2} \mathrm{O}$ (Figure 3) shows that the increase in the $\mathrm{CH}_{2} \mathrm{O}$ rate of evolution lags that of $\mathrm{N}_{2} \mathrm{O}$ by about 40,000 seconds. This behavior is similar to that observed at higher temperatures. Several other products also observed in the higher temperature experiments are dimethylnitrosamine $(m / z=74)$, formamide $(m / z=45), \mathrm{H}_{2} \mathrm{O}$ and CO. The temporal behaviors of these products are similar to those observed at higher temperatures.

Since there is a strong correlation between the identities and temporal behaviors of the products in the new lower temperature experiments and those of the previous higher temperature experiments, it is possible to determine the temperature dependence of the first stages of the thermal decomposition of HMX. The experimental parameters and data collected from experiments with HMX are listed in Table 1. The experiments range in temperature from $175^{\circ}$ to $200^{\circ} \mathrm{C}$ (data from reference 4 is also included in Table 1). HMX samples with mean particle 
diameters of 150 and $600 \mu \mathrm{m}$ were used in the experiments. The diameter of the reaction cell orifice was also varied from $10 \mu \mathrm{m}$ to $100 \mu \mathrm{m}$ in different experiments. Although there may be an effect due to the extent of gas product containment, which is controlled by the orifice diameter, and particle size, these effects are small compared to the variation in the induction times and rates of reaction with temperature.
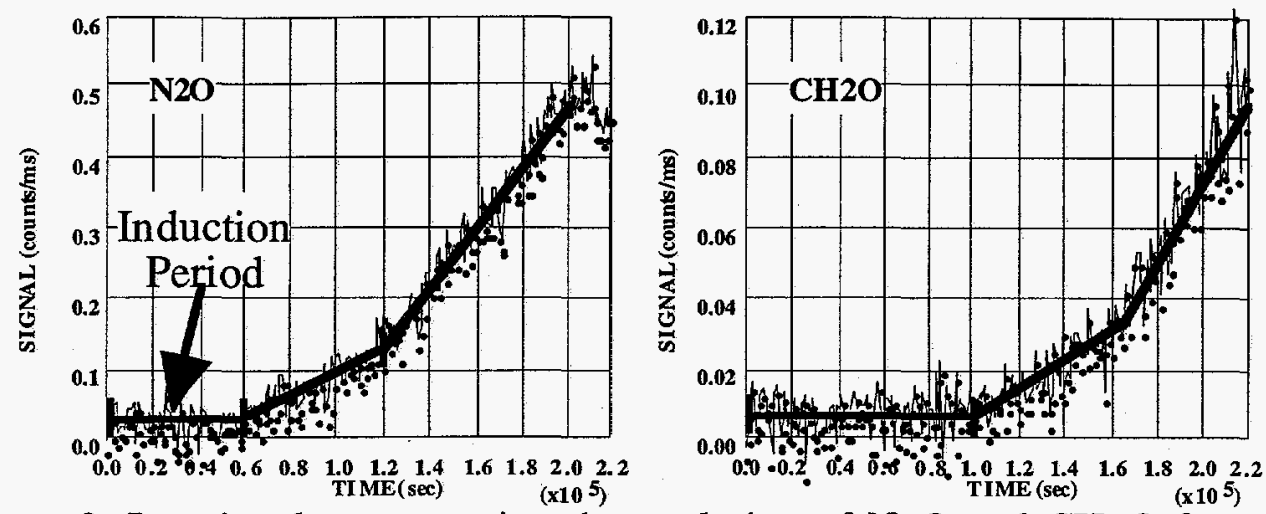

Figure 3. Ion signals representing the evolution of $\mathrm{N}_{2} \mathrm{O}$ and $\mathrm{CH}_{2} \mathrm{O}$ from the thermal decomposition of $\mathrm{HMX}$ at $182^{\circ} \mathrm{C}$.

Table I. HMX THERMAL DECOMPOSITION DATA

\begin{tabular}{|c|c|c|c|c|c|c|}
\hline & Temp $\left({ }^{\circ} \mathrm{C}\right)$ & $\begin{array}{c}\text { Particle } \\
\text { diameter } \\
(\mu \mathrm{m})\end{array}$ & $\begin{array}{c}\text { Orifice } \\
\text { Diameter } \\
(\mu \mathrm{m})\end{array}$ & $\begin{array}{c}\text { Induction } \\
\text { time }(\mathrm{sec})\end{array}$ & $\begin{array}{l}\text { Decomposition rate constant } \\
\left(\mathrm{sec}^{-1}\right) \\
\text { First }\end{array}$ & Second \\
\hline \hline $1 / 2^{*}$ & 175 & 600 & 25 & 270000 & $2.85 \mathrm{E}-07$ & $5.09 \mathrm{E}-07$ \\
\hline 3 & 182 & 600 & 10 & 64000 & $3.97 \mathrm{E}-07$ & $2.30 \mathrm{E}-06$ \\
\hline 4 & 182 & 150 & 10 & 88000 & $4.94 \mathrm{E}-07$ & $9.29 \mathrm{E}-07$ \\
\hline 5 & 182 & 150 & 100 & 62000 & & \\
\hline 6 & 200 & 150 & 100 & 9000 & $3.83 \mathrm{E}-06$ & $8.77 \mathrm{E}-06$ \\
\hline 7 & 210 & 150 & 100 & 2600 & $1.30 \mathrm{E}-05$ & $4.50 \mathrm{E}-05$ \\
\hline 8 & 226 & 150 & 100 & 800 & & \\
\hline 9 & 235 & 150 & 100 & 370 & & \\
\hline
\end{tabular}

* Experiment carried out in two parts. Sample was heated and held at $175^{\circ} \mathrm{C}$ for 220,000 seconds, cooled and removed from the apparatus for 5 days, and then again heated and held at $175^{\circ} \mathrm{C}$ for 220,000 seconds.

INDUCTION PERIOD. The temperature dependence of the induction period is shown in Figure 4. The Arrhenius parameters calculated from the data are $\log (\mathrm{A})=18.2 \pm 0.8$ and $\mathrm{Ea}=$ $48.2 \pm 1.8 \mathrm{kcal} / \mathrm{mole}$. The variation in the results from the three experiments conducted at $182^{\circ} \mathrm{C}$ using different particle sizes and different orifice diameters is shown by the data at $1 / \mathrm{T}=0.0022$ in Figure 4. The two points shown at $1 / \mathrm{T}=0.00223 \mathrm{sec}^{-1}$ are two different estimates for the induction time from experiment $1 / 2$ in which the sample was heated and held at $175^{\circ} \mathrm{C}$ for 220000 seconds, cooled and removed from the apparatus for five days, and then reheated and held at $175^{\circ} \mathrm{C}$ for another 220000 seconds. The shorter induction time was taken from the data collected in the first heating cycle and the longer induction time was taken from the second heating cycle. The acceleratory phase of the decomposition was not readily apparent in the first heating cycle and the data point was based on the first apparent deviation of the $\mathrm{N}_{2} \mathrm{O}$ signal from a constant value. The data from the second heating cycle showed a clear acceleratory period and the induction time is calculated as the sum of the time heated in the first cycle and the normal induction time measured in the second cycle. 
Clearly, this data suggests that under normal storage conditions $\left(<70^{\circ} \mathrm{C}\right) \mathrm{HMX}$ should be stable over the lifetime of any component in which it is used, based on these decomposition

measurements of pure HMX. However, there are several other points that should be considered regarding the decomposition of HMX. First, it is possible that reactions may occur between HMX and other materials that may come in contact with the particle surface. This may occur at lower temperatures than the decomposition of

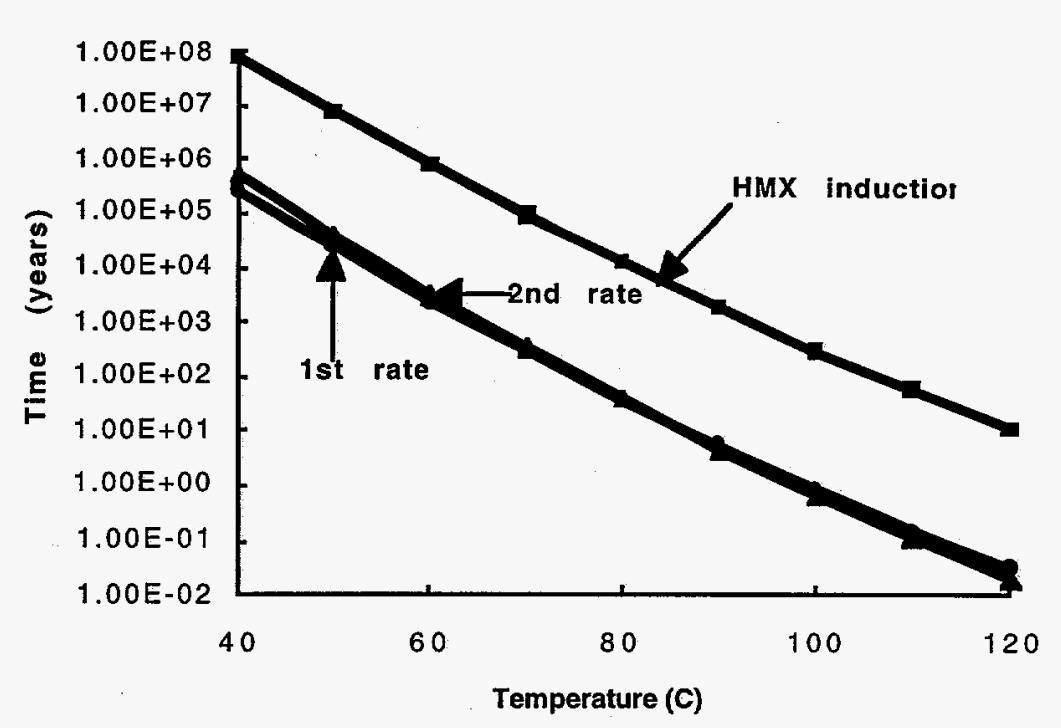

HMX by itself. These interactions may present a long-term aging issue. Second, during the induction period HMX must undergo some significant changes. These changes may be chemical, physical or both. It is unlikely that they would affect the combustion or detonation behavior of these materials, since no significant change in the energy content of the material is observed. However, these changes may affect the thermal or impact sensitivity if they cause significant changes in the way "hot spots" are formed in the material. Third, the decomposition processes that we have studied above $210^{\circ} \mathrm{C}$ also occur at lower temperature. Thus, it is reasonable to assume that the details of the reaction processes that we have observed at higher temperatures also occur at lower temperatures (reaction in the lower temperature B-HMX may differ from the higher temperature $\partial-\mathrm{HMX}$ measured in these studies). This process which was observed in the solid phase decomposition of RDX and HMX is the formation of the mononitroso analogue of the parent compound. From our previous data we believe that the mononitroso analogue is formed within the solid lattice. The conversion of HMX to its mononitroso analogue occurs through scission of the $\mathrm{N}-\mathrm{NO}_{2}$ bond and reaction of the NO within the surrounding "lattice cage". This is consistent with the results of our isotopic crossover experiments using $15 \mathrm{~N}$ labeled HMX, which showed that $75 \%$ of the mononitroso analogue of HMX formed in the experiment did not participate in isotopic scrambling. It is also consistent with the activation energy of $48.2 \pm 1.8 \mathrm{kcal} / \mathrm{mole}$ for the induction period measured in this study which is very close to the $\mathrm{N}-\mathrm{NO}_{2}$ bond energy of approximately $45 \mathrm{kcal} / \mathrm{mole}$. From our thermal decomposition studies of the mononitroso analogue of RDX we have found that it is significantly less stable than RDX and its main decomposition products are $\mathrm{N}_{2} \mathrm{O}$ and $\mathrm{CH}_{2} \mathrm{O}$. This is quite consistent with the products observed in the decomposition of HMX in this study. Thus, from these results, it appears that the process that occurs in the solid phase at low temperature may also be scission of the $\mathrm{N}-\mathrm{NO}_{2}$ bond, reaction of the $\mathrm{NO}_{2}$ within a "lattice cage" to form the mononitroso analogue of HMX, decomposition of the mononitroso HMX within the HMX lattice to form gaseous products that are retained in bubbles or diffuse into the surrounding lattice. These products may affect the sensitivity of HMX significantly.

\section{CONCLUSIONS}

The decomposition of HMX between $175^{\circ}$ and $210^{\circ} \mathrm{C}$ exhibits the same behavior as HMX above $210^{\circ} \mathrm{C}$. The identity and temporal behavior of the products formed in the lower and higher temperature ranges are similar. Thus, the results of mechanistic studies conducted at the higher temperature range are applicable to the reactions at lower temperatures. 
The data from the experiment with the two heating cycles clearly shows that the HMX sample retains the degradation effects of prior heating. Thus, from this initial data, it appears that the effects of the degradation process that occur during the induction period are irreversible. However, further experiments need to be performed to test this more thoroughly.

ACCELERATORY PERIOD. The acceleratory period that commences at the end of the induction period is characterized by two different acceleration rates as illustrated by the $\mathrm{N}_{2} \mathrm{O}$ data shown in Figure 3. The rate constants, derived from averaging the weight loss data measured with the microbalance of the STMBMS over the duration of each acceleratory period, are listed in Table I. There is some variation in the rate constant calculated for the 2 nd acceleratory phase due to the measurement being made on different segments of the acceleratory curve. The weight loss data were corrected for evaporation of HMX in the experiments using the reaction cell with the $100 \mu \mathrm{m}$ diameter orifice. This correction was not necessary in the experiments using the smaller diameter orifices due to the small contribution from evaporation.

The temperature dependence of the 1st and 2 nd acceleratory periods is shown in Figure 5. The Arrhenius parameters for the 1 st acceleratory period are $\log (\mathrm{A})=$ $17.15 \pm 1.5$ and $\mathrm{Ea}=48.9 \pm 3.2$

$\mathrm{kcal} / \mathrm{mole}$. The Arrhenius parameters for the 2 nd acceleratory period are $\log (\mathrm{A})=19.1 \pm 3.0$ and $\mathrm{Ea}=52.1 \pm 6.3 \mathrm{kcal} / \mathrm{mole}$.

\section{MODEL TO PREDICT LOWER TEMPERATURE BEHAVIOR FOR HMX}

The data from the induction and the two acceleratory periods can be used to estimate the extent of decomposition as a function of sample temperature and time. It can also be used to estimate the extent of degradation at lower temperatures over long periods of time.

The fraction, Fr, of HMX that has decomposed up to a given point in time, $t$, when held at a temperature, $T$, is given by

$$
\operatorname{Fr}=\left[1-\operatorname{Exp}\left(-k_{1} t_{d 1}\right)\right]+\left[1-\operatorname{Exp}\left(-k_{2} t_{d 2}\right)\right]
$$

where the rate constants for the 1 st $\left(\mathrm{k}_{1}\right)$ and 2 nd $\left(\mathrm{k}_{2}\right)$ acceleratory periods are given by

$$
\log \left(k_{1}\right)=1714-\frac{10664}{T}
$$

and

$$
\log \left(k_{2}\right)=1912-\frac{11374}{T}
$$

the time in each acceleratory period is given by

$$
\left.t_{d 1}=\operatorname{Min}\left(t-t_{i n d}\right) t_{f}\right)
$$

and 
the induction time is given by

$$
\log \left(1 / t_{\text {ind }}\right)=18.23-\frac{10525}{T}
$$

and $\mathrm{t}_{\mathrm{f}}$ is the time of the transition from the first to the second acceleratory region and is given by

$$
t_{f}=-\operatorname{Ln}\left(1-f_{t}\right) / k_{1}
$$

where $f_{t}$ is the fraction of decomposition at which there is a transition from the 1 st to the 2nd acceleratory phase, and $\mathrm{t} f \mathrm{~m}$ is the time associated with the maximum fraction of decomposition, $\mathrm{f}_{\mathrm{m}}$, that this model is developed to predict and is given by

$$
t_{f m}=-\operatorname{Ln}\left(1-f_{m}+f_{t}\right) / k_{2} .
$$

The transition fractions used in the model are $f_{t}=0.05$ and $f_{m}=0.2$. The value for $f_{t}$ is determined from the break points between the 1 st and 2 nd acceleratory periods measured in the experiments. The value of 0.2 for $f_{m}$ is selected because this approximates the amount of decomposition that occurs through the acceleratory phase.

The fraction of decomposition as a function of time at several different temperatures is shown in Figure 6. For example, to achieve 5\% decomposition requires the sample to be maintained at $190^{\circ} \mathrm{C}$ for approximately 19 hours.

\section{HMX LONG-TERM DECOMPOSITION}

The length of time predicted for the duration of the induction period and the point at which $0.01 \%$ of the sample has decomposed based on the rate constants for the first and second acceleratory periods is shown in Figure 7 for a set of temperatures varying between $20^{\circ}$ and $130^{\circ} \mathrm{C}$. The data in the table shows that if the sample is maintained at $120^{\circ} \mathrm{C}$ the induction period will last for 10 years before gas starts to be released in the first acceleratory period. Whereas, if the reaction kinetics that control the decomposition was based on the

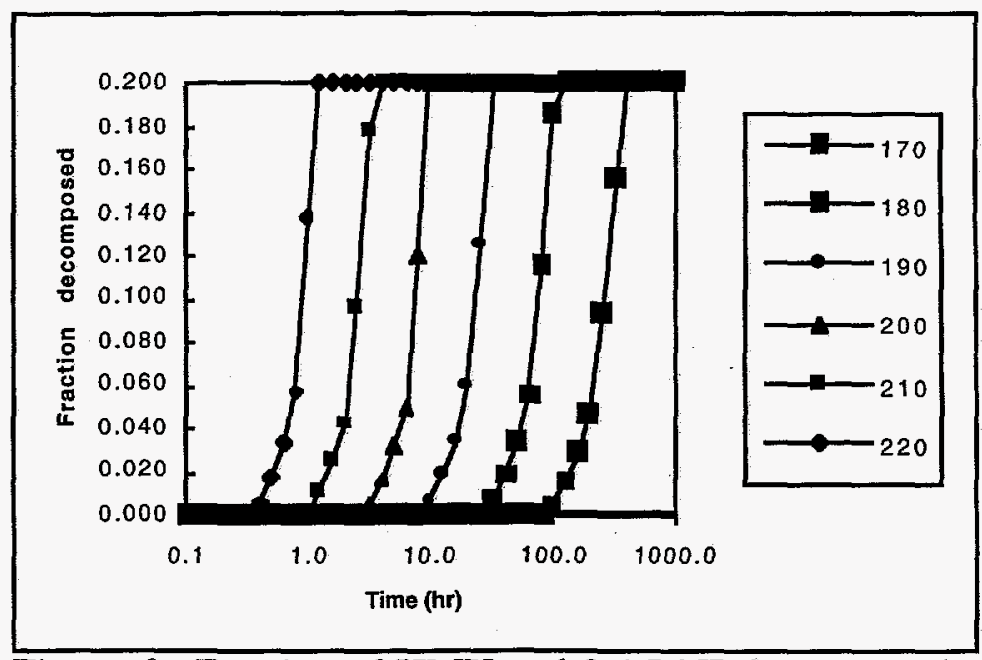

Figure 6. Fraction of HMX and 2,4-DNI decomposed up to $20 \%$ as a function of time and temperature $\left({ }^{\circ} \mathrm{C}\right)$.

reactant rates that characterize the two acceleratory periods, then the sample only needs to be maintained between $80^{\circ}$ and $90^{\circ} \mathrm{C}$ to undergo $0.01 \%$ decomposition in ten years. This illustrates the importance of the process that occurs in the induction period in contributing to the long-term stability of $\mathrm{HMX}$. For example, at $70^{\circ} \mathrm{C}$ the induction period would last 85,000 years, whereas, decomposition controlled by solely the acceleratory period reactions would occur over 200 to 300 years. 
The early stages of the decomposition of HMX can be divided into three segments, an induction period followed by two acceleratory periods. The end of the induction period is characterized by the increase in the rate of $\mathrm{N}_{2} \mathrm{O}$ evolving from the sample. The increase in the rate of evolution of $\mathrm{CH}_{2} \mathrm{O}$ always lags that of $\mathrm{N}_{2} \mathrm{O}$, suggesting that $\mathrm{CH}_{2} \mathrm{O}$ is initially retained in the HMX lattice. Other products such as formamide and dimethylnitrosamine are also observed.

The A-factors and activation energies for the induction period and two acceleratory periods are $(\log (\mathrm{A})=18.2 \pm 0.8, \mathrm{Ea}=48.2 \pm 1.8 \mathrm{kcal} / \mathrm{mole}),(\log (\mathrm{A})=17.15 \pm 1.5$ and $\mathrm{Ea}=48.9 \pm 3.2$ $\mathrm{kcal} / \mathrm{mole}),(\log (\mathrm{A})=19.1 \pm 3.0$ and $\mathrm{Ea}=52.1 \pm 6.3 \mathrm{kcal} / \mathrm{mole})$, respectively. These activation energies are similar to $\mathrm{N}-\mathrm{NO}_{2}$ bond energy in $\mathrm{HMX}$.

Using the Arrhenius parameters determined from the measurements, estimates of the length of time that an HMX containing sample must be held at a given temperature to achieve a desired fraction of decomposition can be determined. This data can be used for preparing samples for testing the effects of thermal degradation on sensitivity and burn rates.

Extrapolating the HMX thermal decomposition results to lower temperatures shows that the degradation is not extensive at the upper temperature limit of the normal stockpile to target sequence, $70^{\circ} \mathrm{C}$. However, raising the temperature to $120^{\circ} \mathrm{C}$ would have a significant effect on the material if it behaves as measured in the present experiments. If for some reason the stability attributed to the induction period were lost and the rate of reaction were controlled by the reactions occurring in the acceleratory phase, then raising the temperature to $85^{\circ} \mathrm{C}$ would cause significant changes in the material.

The similarity of the results of the lower temperature experiments carried out in this study to our previous mechanistic studies of HMX and RDX at higher temperature allows us to suggest that the following process probably occurs in the early stages of the solid phase decomposition of HMX: scission of the $\mathrm{N}-\mathrm{NO}_{2}$ bond, reaction of the $\mathrm{NO}_{2}$ within a "lattice cage" to form the mononitroso analogue of HMX and decomposition of the mononitroso HMX within the HMX lattice to form gaseous products that are retained in bubbles or diffuse into the surrounding lattice.

Further studies are needed to accurately characterize the effects of particle size, gas containment, and cycling the sample temperature on the thermal decomposition process. However, several experiments conducted in the present study, in which these parameters were varied, indicate that these effects are secondary compared to the variation due to temperature.

\section{ACKNOWLEDGMENTS}

The authors wish to thank D.M. Puckett for assistance in collecting the mass spectrometry data. This work was supported by the Memorandum of Understanding between the Office of Munitions and the U.S. DOE, the U.S. Department of Energy under Contract DE-AC0494AL85000, and the U.S. Army, ARDEC.

1 R. Behrens, Jr.; Rev. Sci. Instrum. 58, 451-461, 1987.

2 a) R. Behrens, Jr.; Int. J. Chem. Kin. 22, 135-157, 1990. b) R. Behrens, Jr.; Int. J. Chem. Kin. 22, 159-173, 1990.

3 R. Behrens, Jr.; J. Phys. Chem. 94, 6706-6718, 1990.

4 R. Behrens, Jr. and S. Bulusu; J. Phys. Chem. 95, 5838-5845, 1991.

5 R. Behrens, Jr. and S. Bulusu; J. Phys. Chem. 96, 8877-8891, 1992.

6 R. Behrens, Jr. and S. Bulusu; J. Phys. Chem. 96, 8891-8897, 1992.

7 R. Behrens, Jr. and S. Bulusu; Mat. Res. Soc. Symp. Proc., 296, p. 18-24, 1993.

\section{DISCLAIMER}

\footnotetext{
This report was prepared as an account of work sponsored by an agency of the United States Government. Neither the United States Government nor any agency thereof, nor any of their employees, makes any warranty, express or implied, or assumes any legal liability or responsibility for the accuracy, completeness, or usefulness of any information, apparatus, product, or process disclosed, or represents that its use would not infringe privately owned rights. Reference herein to any specific commercial product, process, or service by trade name, trademark, manufacturer, or otherwise does not necessarily constitute or imply its endorsement, recommendation, or favoring by the United States Government or any agency thereof. The views and opinions of authors expressed herein do not necessarily state or reflect those of the United States Government or any agency thereof.
} 